\title{
Optimizing Mentor/Mentee Relationships in Academia
}

\author{
Barbara E. Marino, Sandra A. Yost \\ Loyola Marymount University/ University of Detroit Mercy
}

\section{Introduction}

The demands of a tenure track appointment at a university can seem overwhelming to a beginning faculty member. Many new engineering professors begin such appointments immediately after a Ph.D. program or post-doctoral appointment. The decade or so of academia sitting in the student's desk and serving as a researcher in the laboratory does not provide adequate preparation for life behind the podium. Launching a research program, obtaining funding, securing laboratory facilities and equipment, teaching courses, and weeding through the seemingly countless requests to serve on university and research-related committees and activities are all demands placed on new faculty members. Unseen to most graduate and doctoral students, these tasks present an imposing reality to the beginning faculty member.

Decisions at the beginning of a tenure-track appointment regarding the use of limited time can have lasting effects on one's professorial career. Successfully handling the demands of a tenure track appointment and negotiating the "tenure gauntlet" requires an astute balancing act. Having a skilled mentor to assist in choosing appropriate activities and career strategies can help to "demystify" the tenure process and to ensure success.

Mentoring programs, some formal, some informal, can be found throughout business and education ${ }^{1-4}$, yet not all are effective. This is due in part to a misunderstanding of the role of both mentor and mentee. Furthermore, much of the available literature on mentoring in academia addresses the mentorship of graduate students, not new faculty colleagues. Therefore, these fledgling professors are often neglected.

This paper presents the results of interviews with new engineering faculty on their experience at the receiving end of mentoring. Important techniques for developing a good mentoring relationship with a senior colleague and practical suggestions for making the mentoring relationship work are explored. New faculty members will find guidance in choosing a mentor and in using the mentoring relationship to enhance their progress toward earning tenure. Faculty who are or would like to be mentors will find useful advice for growing in this important role in their junior colleagues' careers.

\section{Responsibilities of a New Faculty Member}

An important goal of a new faculty member is to attain tenure. Most faculty manuals, regardless of the institution, state that the decision to award tenure is primarily based on three areas: research, teaching and service. Since many new faculty members begin their 
appointments immediately after a Ph.D. program or post-doctoral appointment, they are often prepared to do research, but have not received adequate preparation for the many other aspects of a professorial appointment.

Performing research is just one of the tasks a new faculty member must tackle in developing a successful research program. Laboratory facilities and equipment must be secured, and graduate students must be recruited and maintained. Departments also expect new faculty members to obtain funds from both internal and external sources. Most importantly, journal publications and conference appearances must be frequent and of an appropriate caliber.

Succeeding as an educator provides a separate set of challenges. A new faculty member must learn how to write and deliver lectures effectively. Assignments and exams must be designed to test the students' understanding of material without unnecessarily overloading the students with work or the professor with grading. A new educator must also learn to accept criticism from students and other educators in order to continually improve courses and teaching techniques.

Often neglected, but not unseen is the responsibility of service. Although service is not usually greatly emphasized, a new faculty member is at no loss for opportunities to fulfill the service requirement. Weeding through the seemingly endless requests to serve on university and research-related committees for advantageous and interesting opportunities is an often overwhelming yet necessary task.

Balancing limited time to meet these demands can be difficult and confusing; however, decisions on the use of time made at the beginning of a tenure-track appointment can have lasting effects on one's career. New faculty members need guidance to find the optimal allocation of time and resources for these vital duties. Otherwise, an entire semester can be swallowed up in committees, lesson plans, or research, when a tenure track professor needs to be working towards all three.

Gaining insight into these new responsibilities from someone who has faced them before can be extremely helpful. Finding the right mentors and developing good relationships with them are essential for helping new faculty members prioritize their responsibilities, manage time effectively, and navigate the treacherous waters of their early years.

\section{Interview Demographics}

For this study, a questionnaire was developed to ascertain the mentoring experiences of new engineering faculty (see Figure 1). The questionnaire was sent to 52 engineering educators. The 17 new faculty who responded represent a cross section of the new faces in engineering education. Men and women split the group equally, 53\% and 47\% respectively. The new faculty work in both large universities, where research is emphasized, and in small universities, where teaching is of primary importance. The results span the country from California to Massachusetts and from North Dakota to Florida. Most of the respondents are in tenure-track positions; however, the $18 \%$, who are visiting assistant professors, were included in this study because they 
provided valuable input. On average, the group had less than 2 years of experience in their position (1.8 years). Most notably, only $47 \%$ of the respondents have mentors.

\footnotetext{
1. Name.

2. School.

3. Are you in a tenure track appointment? If so, for how many years?

4. Do you have a mentor?

5. If so, how would you classify your mentor? Invisible, Incorrigible (bad) or Invincible (good)?

6. How would you say your answer to question 5 has effected your progress toward tenure? Personal experiences and anecdotes would be very helpful.

7. Do you have any suggestions for fostering or improving the mentor/mentee relationship?
}

Figure 1: Interview Questions

\section{Archetypal Mentors}

Preliminary discussions conducted prior to questionnaire interview, have revealed three basic mentor archetypes, which we call "The Invisible Mentor," "The Incorrigible Mentor," and "The Invincible Mentor." The following describes each archetype and includes illustrative excerpts from the formal interview process.

The Invisible Mentor. 59\% of the respondents have invisible mentors. This includes those new faculty that claimed not to have a mentor at all, the truly invisible mentor. Other respondents in this category have what on paper might look like the perfect mentor. These mentors are very successful and quite personable, but they are just too busy to be effective. They do not have the time to invest in all that a mentee needs. On the other hand, new faculty members also contribute to this situation by not actively seeking mentors.

Tell tale signs of the Invisible Mentor:

- Does not exist.

- Is too busy.

- $\quad$ Does not initiate dialogue.

Many of the new educators we heard from felt they needed more from a mentor. Whether not having a mentor or having a mentor that was too busy to be helpful with the day to day issues, new faculty found they needed advice on everything from housing to the inner workings of the department to proposal writing.

One respondent, however, was against the idea of one "official" mentor. His preference is to get advice when needed, but not to seek approval from anyone. He felt that having one mentor would be to rely too heavily on one persons opinion, and would be more like having a supervisor. His advice: "Don't follow footsteps; make new tracks." 
The Incorrigible Mentor. $6 \%$ of the respondents have incorrigible mentors. As overwhelming and stressful as they can be, the first few years of an academic appointment can be even worse with a bad mentor. These mentors can vary from being not aggressive enough, letting the mentee flounder, to being too aggressive, determining the mentee's path for him or her.

Tell tale signs of the Incorrigible Mentor:

- Has a poor track record with mentees and graduate students.

- Dominates collaboration.

- Is petty.

- Is not aggressive enough.

- Is too aggressive.

- $\quad$ Lacks success in grant writing.

- Has a bad standing with the rest of the faculty.

One respondent has had the unfortunate experience of being treated like a graduate student by her mentor. This incorrigible mentor is interested in only what he can get out of the relationship as far as publications and funding are concerned. His lack of concern for the success of his mentee certainly does not serve the purpose for which he was assigned.

The Invincible Mentor. 35\% of the respondents have invincible mentors. Having a skilled mentor to assist in choosing appropriate career strategies can help to "demystify" the tenure process and to increase greatly the chances of success. A good mentor provides input on appropriate committee involvement, research directions, funding sources, and even teaching techniques. Furthermore, an effective mentor can anticipate problems and suggest solutions all along the tenure track.

Tell tale signs of the Invincible Mentor:

- $\quad$ Provides timely feedback.

- Collaborates.

- Values mentees' contributions.

- Supports and encourages.

- Serves as a role model.

- Succeeds in research.

- Talks straight.

- Helps prioritize.

- Has a compatible personality.

Most of the mentees toting claims of an invincible mentor looked to their mentors "to provide a wealth of practical day-to-day information about how to go about doing things as well as more philosophical strategies to get tenure." This requires a substantial time commitment on the part of the mentor. The mentors who fall into this archetype are willing to invest the time and energy necessary to be a successful mentor, even if this occasionally requires "taking a back seat" to the achievements of their mentees. 
Mentees valued a mentor who had the same priorities and social interests. Moreover, successful relationships were formed out of mutual respect and common interests. One respondent compared the relationship with a good mentor to that of a big brother or sister. A mentor is often called on to show the mentee the ropes, protect the mentee from harm, and serve as a role model.

\section{Choosing Your "Invincible Mentor"}

While some new faculty report that they were chosen by their mentor, most must take the first step by asking a senior colleague to serve as a mentor. In a few cases, new faculty may be served by a formal mentoring program which automatically assigns them a senior colleague as their mentor. More frequently, no formal mentoring program exists, and the new faculty member must either "go it alone" or seek out and initiate a mentoring relationship with one or more colleagues.

In choosing a mentor or mentors, be aware that the best choice may not be in your department or even at your institution. Your mentor may not be from the same racial/ethnic background or be of the same sex. The choice of mentor will depend on what kind of help you need in advancing in your career. At very early stages, it will be important to have someone who understands the requirements for tenure and promotion at your institution, and is willing to give you an honest assessment of your chances of success, as well as strategies for improving those chances. Most likely that person will be someone from your institution.

If you are female or from a racial minority group, you may have no role models in your department who understand the issues you must face as a member of such a group. In such a case, you may want to have more than one mentor. For example, a new female faculty member may wish to have a male colleague from her own department be her primary guide in the tenure and promotion process, but may also choose to have a female mentor from another department with whom she can discuss the issues arising from being a woman in a predominantly male discipline.

Choosing a world-famous and well-connected mentor who has little or no time for you may not be the best choice. The mentor's interest in your success is perhaps the most important factor in a good mentoring relationship. Beyond that, the person or persons you choose will be of the most help if they have been successful in achieving tenure, establishing a research program, directing graduate students, demonstrating excellent teaching, or whatever it is you hope to learn from them. Mentors should be colleagues you see frequently, not someone who is never in the office. They should also be well-respected by colleagues in the department, college, and university. The ideal mentor also is articulate and willing to speak out in support of mentees at the appropriate times.

\section{Fostering a Good Relationship With Your Mentor}

Once you have chosen a mentor or mentors who can help you to succeed in your career, it takes some initiative on your part to make the mentoring relationship work to your benefit. In this section we suggest some specific strategies for helping the mentor to help you. 
Remember first of all, that like any adult relationship, the relationship with a mentor should be a mutual relationship. This presumes you have something of value to bring to the relationship, perhaps a shared interest in research and/or teaching. Obviously, a more experienced colleague may give more, while the mentee will operate in more of a "taking" mode, but it is important for the new faculty member to realize that the relationship will not work well for long if it is one-sided. This means that you will have to be clear and direct with your mentor about your expectations and how you envision that person helping you to grow as a colleague.

One practical structure for developing the mentoring relationship is to set aside a regular time to meet, just to discuss issues regarding your professional development. Having such a meeting every few months (or more frequently if possible) will help to keep you focused on what you need to be addressing to insure success in the tenure and promotion process. You might invite your mentor to one of your classes so that you can receive helpful feedback about your teaching style. This might also lead to discussions about innovative teaching strategies on which you might collaborate with your mentor.

The mentor plays an important role in helping you to make useful connections with others, both inside and outside your institution, who can assist you in establishing and implementing plans for research and innovative teaching. If your mentor is active in a professional society or is a frequent presenter at conferences, you should ask the mentor to introduce you to some of the key people who can help you to get involved in meaningful work. A mentor with good contacts in industry can help you to find the right people with whom to collaborate on applied research funded by industry. Inside your institution, your mentor can introduce you to people on campus who may be in a position to speak favorably of you when your tenure case is under consideration.

Ask your mentor to give you copies of successful as well as unsuccessful grant proposals so that you have an idea of what is expected when you begin to write your own proposals. Find out from your mentor the best ways to for you to seek external funding, and the best sources of funding for what you want to do.

Many beginning faculty members make the mistake of agreeing to serve on too many committees. While service remains one of the criteria for tenure and promotion at most institutions, its relative weight in tenure decisions usually falls well below that of the teaching and research components. A good mentor can help you to decide which of the many opportunities to serve will be most appropriate at each stage of your career.

It may happen that you and/or your mentor decide that the relationship is not working out as expected. In such cases, it may be best to simply acknowledge this and move on. Like any relationship, the mentoring relationship is one which sometimes defies understanding. Compatibility with a mentor is something that often takes time to evaluate, and there need not be any hard feelings should you decide that the relationship is not working. A former mentor can still be a powerful ally at critical times in your career, so try not to burn any bridges if you outgrow your mentor. 


\section{Conclusion}

The strategies suggested in this paper are meant to assist new engineering faculty members in choosing a mentor and getting the most out of the mentoring relationship. Effective mentoring can be a critical factor in positive tenure outcomes. The interviews used for this paper revealed a need for both mentors and mentees to re-examine their roles. While mentees need to seek out appropriate mentors and develop that relationship, mentors must become more aware of the needs of new faculty and the benefits of assisting them in their adjustment to university positions. Further study could compare official and unofficial mentoring systems as well as university incentives for mentoring. Ultimately, these relationships when optimized benefit not only the mentor and mentee, but also the university at large as their faculty begin collaborating, cooperating, and communicating invincibly.

\section{References}

[1] Anon., "Women Engineers: Why So Few?", J. Management in Engineering, v 10, n 5, pp. 20-23, Sept.-Oct. 1994.

[2] Sherwood, J. L., et al., "Faculty Mentoring: A Unique Approach to Training Graduate Students How to Teach", J. Engr. Educ., v 86, n 2, pp. 119-123, Apr. 1997.

[3] Reohr, J. R., "Mentor and Colleague Relationships in Academia”, ERIC Doc. No. ED215640, 1981.

[4] Carter, H. M., "Making it in Academia: Gurus Can Get You There?”, ERIC Doc. No. ED235758, 1982.

BARBARA E. MARINO is an Assistant Professor in the Department of Electrical Engineering and Computer Science at Loyola Marymount University. She teaches courses in computer engineering, and her research interests include image processing and electronic imaging. Barbara has been an active member of ASEE since 1991.

SANDRA A. YOST is an Assistant Professor in the Department of Electrical Engineering and Computer Science at the University of Detroit Mercy. She is active in several professional societies, including IEEE, ASEE, and SWE. Her interests include discrete time system theory, control system applications, and engineering education. 